\title{
IDENTIFICATION A DNA DAMAGE-INDUCED ALTERNATIVE SPLICING PATHWAY THAT REGULATES p53 AND CELLULAR SENESCENCE MARKERS
}

\author{
Jing Chen ${ }^{1,2}$, John Crutchley ${ }^{1,2}$, Dadong Zhang ${ }^{2}$, Kouros Owzar ${ }^{2,3}$, and Michael B. \\ Kastan $^{1,2}$ \\ 1'Department of Pharmacology and Cancer Biology, Duke University School of Medicine, Durham, \\ NC 27710 \\ ${ }^{2}$ Duke Cancer Institute, Duke University, Durham, NC 27710 \\ ${ }^{3}$ Department of Biostatistics and Bioinformatics, Duke University, Durham, NC 27710
}

\begin{abstract}
Cellular responses to DNA damage are critical determinants of cancer development and agingassociated pathogenesis. Here we report a novel DNA damage response pathway that regulates alternative splicing of numerous gene products, including the human tumor suppressor p53, and controls DNA damage-induced cellular senescence. In brief, ionizing irradiation (IR) inhibits the activity of hSMG-1, a phosphoinositide-3-kinase-like kinase (PIKK) family member, reducing the binding of hSMG1 to a specific region of p53 precursor mRNA near exon 9 and promoting the binding of ribosomal protein L26 (RPL26) to p53 pre-mRNA. RPL26, in turn, is required for the recruitment of the Serine/Arginine-rich splicing factor, SRSF7, to 553 pre-mRNA and generation of alternatively spliced $p 53 \beta$ RNA. Disruption of this pathway via selective knockout of $p 53 \beta$ by CRISPR/Cas9 or down-regulation of pathway constituents significantly reduces IR-induced senescence markers and cells lacking $\mathrm{p} 53 \beta$ expression fail to transcriptionally repress negative regulators of cellular senescence and aging.
\end{abstract}

\section{Keywords}

DNA damage; alternative RNA splicing; p53; senescence

\section{INTRODUCTION}

The integrity of nuclear DNA in mammalian cells is constantly challenged by exposure to exogenous damaging agents (e.g. ionizing or UV irradiation, various chemicals), by the generation of reactive intracellular metabolites (e.g. oxygen radicals), and by DNA

To whom correspondence should be addressed: Michael B. Kastan, MD, PhD, Duke Cancer Institute, Mail Box 3917, 10 Bryan Searle Drive, Seeley Mudd Building, Durham, NC, USA, Tel: (919)-684-3052; Fax: (919)-681-7385; michael.kastan@duke.edu. AUTHOR CONTRIBUTIONS

J. Chen and M.B.K. conceived and designed the study and analyzed the data. J. Chen and J. Crutchley performed the experiments.

D.Z. and K.O. analyzed microarray data. J. Chen and M.B.K. wrote the manuscript with input from all authors. 
alterations caused by shortening or aberrations of chromosomal ends or abnormal DNA replication intermediates (1). Suboptimal cellular responses to DNA damage contribute to cancer development and to aging-associated pathogenesis (2). Conversely, many cancer therapeutics work by damaging DNA, thus making the cellular responses to damage important determinants of outcomes of cancer therapies.

The p53 tumor suppressor is a key player in cellular responses to DNA damage and other stresses. Levels of p53 protein increase after DNA damage and typically lead to cell cycle arrest or programmed cell death (1). This stress-induced protein induction is controlled in part by an increased half-life of p53 protein resulting from inhibition of HDM2-mediated proteasomal degradation $(3,4)$. Increased translation of p53 mRNA after DNA damage also contributes to $\mathrm{p} 53$ induction, a process regulated by the damage-induced binding of ribosomal protein RPL26 to a double-strand RNA structure formed by base-pairing between the sequences in the $5^{\prime}$-UTR and $3^{\prime}$-UTR of p53 mRNA (5). Disruption of this translational control blunts p53 induction and p53-mediated growth arrest and apoptosis $(5,6)$.

Alternative splicing of pre-mRNA products is increasingly appreciated as an additional mechanism to expand RNA and protein diversity $(7,8)$. Mutations that perturb alternative splicing (AS) patterns are reported in a variety of human hereditary diseases and cancer $(9$, 10). For example, AS isoforms of apoptotic gene products, including members of the Bcl-2 family, are generated after DNA damage and appear to influence cell death propensities (11). Alternatively spliced forms of p53 mRNA and protein have been noted and have been suggested to contribute to the versatility of p53 mediated cellular responses (12). Expression of these different forms of p53 appears to vary in different tissues and abnormal expression of these variants has been described in some cancers and linked to patient clinical outcomes. Nine different alternatively spliced p53 mRNA products, generated by internal promoter usage or intron retention, have been reported $(13,14)$. For example, retention of part of intron 9 (referred to as "exon $9 \beta$ " in this manuscript) generates the p53 $\beta$ splice variant, which encodes a $\mathrm{C}$-terminal truncated $\mathrm{p} 53$ protein due to introduction of a premature termination codon (PTC). This truncated p53 RNA is typically degraded in cells via nonsense mediated RNA decay (NMD), but levels of p53 $\beta$ RNA and protein appear to increase in some cells as they exhaust their replicative capacity and become senescent (15, 16). While overexpression of $\mathrm{p} 53 \beta$ has been reported to trigger replicative senescence or apoptosis in different settings, little is known about the cellular or extra-cellular factors which regulate this alternative splicing.

As we conducted studies of IR-induced translational regulation of $\mathrm{p} 53$, we noted an increase in the generation of the $\beta$ isoform of p53 RNA. Characterization of this unexpected finding uncovered a novel DNA damage-induced alternative splicing pathway that is required for increases in the levels of p53 $\beta$ as well as other alternatively spliced gene products.

Generation of $\mathrm{p} 53 \beta$ after IR was dependent on inhibition of the hSMG1 kinase, the binding of RPL26 to p53 pre-mRNA, and the recruitment of the SRSF7 splicing factor. Similar signaling steps and induction of $\mathrm{p} 53 \beta$ were seen after cellular exposure to the basedamaging agent, methylmethanesulfonate (MMS). Interestingly, we noted that UV irradiation, which introduces bulky DNA adducts, also induces RPL26-dependent alternative splicing of p53 mRNA, but in this case the $\Delta \mathrm{p} 53$ isoform, rather than the p53 $\beta$ isoform, is 
induced. Characterization of the functional relevance of $\mathrm{p} 53 \beta$ induction demonstrated that overexpression of this p53 isoform induces a cellular senescent phenotype, as previously reported (17-19), and that this cellular outcome was dependent on the ability of the spliced protein product to bind to DNA and regulate transcription. Supporting a critical role for $\mathrm{p} 53 \beta$ and for this pathway in IR-induced cellular senescence, p53 $\beta$ knockout or modulation of the other pathway regulators reduces IR-induced markers of cellular senescence. Thus, these studies demonstrate the existence of a previously unreported component of the DNA Damage Response (DDR) Pathway whereby DNA damage induces alternative splicing of p53 and other gene products and the induction of p53 $\beta$ appears to be involved in IR-induced cellular senescence.

\section{RESULTS}

\section{DNA damage increases levels of alternative splice forms of human p53}

We previously demonstrated that ionizing irradiation of cells causes RPL26 protein to bind to a double-strand RNA structure created by base-pairing of sequences from the $5^{\prime}$ and $3^{\prime}$ UTRs of p53 mRNA and enhances p53 translation after DNA damage $(5,6)$. Ionizing irradiation (IR) promotes the binding of RPL26 to p53 mRNA by inhibition of HDM2, which both mediates degradation of RPL26 and blocks binding of RPL26 to p53 mRNA (32). While characterizing the transcriptome bound by RPL26 after IR, we detected an abundance of the p53 $\beta$ splice variant in the RPL26 immunocomplex (Figure S1A). In unstressed cells, $\mathrm{p} 53 \beta \mathrm{mRNA}$ is rapidly degraded by the NMD pathway due to a premature termination codon inside the retained exon $9 \beta$. Since NMD takes place mainly in the cytosol $(33,34)$ and could complicate assessments of alternative splicing of p53 mRNA, we quantitated the levels of 553 pre-mRNA (unspliced message), total spliced p53 mRNA, and p53 $\beta$ variant mRNA (spliced messages) specifically in the nucleus (Figure 1A). Based on current information of all identified p53 splice variants (reviewed in (35)), no alternative splicing events have been observed at introns 7 and 8 . Splicing of intron 7 can serve as a measure of total spliced p53 mRNA, while retention of intron 8 is only seen in p53 premRNA. We designed specific primers that cover these two regions to measure levels of total spliced (TS) p53 mRNA and unspliced p53 pre-mRNA, respectively. The ratio of spliced/ unspliced message is a quantitative assessment of the relative amount of spliced mRNA.

Levels of nuclear p53 $\beta$ mRNA in MCF-7 breast cancer cells rapidly and transiently increased after IR, while the levels of p53 pre-mRNA and total spliced p53 message remained unchanged (Figure 1A, bottom left panel, Figure S1B). A significantly increased ratio of the spliced/unspliced mRNA after IR suggests a preferential RNA splicing to generate the $\beta$ variant after damage (Figure 1A, bottom right panel). Concomitantly, p53 $\beta$ protein levels also gradually increased and peaked around thirty minutes after IR (Figure 1B). In contrast, full-length $\mathrm{p} 53$ protein usually achieves its maximum accumulation around two hours after damage. The induction of $p 53 \beta$ mRNA after IR was observed in a variety of cell types, including tumor lines such as HCT116 colorectal cells (data not shown) and SY5Y neuroblastoma cells (Figure S1A) and human primary adult fibroblasts (Figure 1C). 


\section{hSMG-1 is a negative regulator of the alternative splicing of $p 53 \beta$}

The ATM protein kinase is a central mediator of many cellular responses to IR, including induction and phosphorylation of p53 protein (36). To assess the potential role of ATM in mediating IR-induced increases in p53 $\beta$ mRNA, we treated MCF-7 cells with a small molecule inhibitor of the ATM kinase, CP466722 (CP) (23). As expected, CP treatment effectively blunted IR induction of full-length $\mathrm{p} 53$ protein (Figure 2A, top band), an ATMdependent induction. In sharp contrast, $\mathrm{CP}$ treatment not only failed to block IR-induced generation of $\mathrm{p} 53 \beta$ mRNA, it instead robustly and sustainably increased p $53 \beta$ mRNA (Figure S2A) and protein levels (Figure 2B, Figure S2A) in the absence of IR and further enhanced $\mathrm{p} 53 \beta$ protein production after IR in primary fibroblasts (Figure $2 \mathrm{~A}$ ). Similar to the observation with IR (data not shown), p53 $\beta$ siRNA blunted the induction of $\mathrm{p} 53 \beta$ by $\mathrm{CP}$ at both the mRNA and protein levels (Figure S2B) and had no effect on the levels of full-length $\mathrm{p} 53$, thus confirming a specific impact on the alternatively spliced form of p53.

These results suggested that inhibition, rather than activation, of ATM could be contributing to generation of the $p 53 \beta$ isoform. Since all kinase inhibitors affect multiple kinases, we attempted to more specifically explore the impact of the ATM kinase on $553 \beta$ generation by using cells treated with ATM siRNA and cells in which the ATM gene had been deleted by use of CRISPR/cas9 genomic manipulation. Unexpectedly, neither short term (ATM siRNA) nor long term loss of ATM (ATM CRISPR knock-out) increased p53 $\beta$ levels nor affected the induction of $\mathrm{p} 53 \beta$ by $\mathrm{CP}$ (Figure $2 \mathrm{C}$, Figure $\mathrm{S} 2 \mathrm{C}$ ). These results suggested that the $\mathrm{CP}$ mediated induction of $\mathrm{p} 53 \beta$ was occurring via inhibition of some other kinase. ATM protein is a serine/threonine protein kinase and a member of the phosphoinositide 3-kinase-related protein kinase (PIKK) family, which includes ATR, DNA-PK, and hSMG-1. Like ATM, all three of these kinases are genotoxic stress responsive kinases $(1,37)$. In addition, hSMG-1 is a key kinase in the nonsense-mediated mRNA decay (NMD) pathway, where it phosphorylates the Upf1 protein (38). The NMD pathway is an RNA surveillance mechanism that targets RNAs with premature termination codons (such as p53 $\beta$ ) for degradation. Phosphorylated Upf1 facilitates the formation of NMD complex and executes the degradation process. Previous characterization of CP had demonstrated that it does not inhibit either ATR or DNA-PK (23) and the DNA-PK inhibitor, Nu 7026, failed to induce p53 $\beta$ (Figure S2D), thus raising the possibility that hSMG-1 could be the relevant kinase involved in $\mathrm{p} 53 \beta$ induction.

Treatment of MCF-7 cells with hSMG-1 siRNA increased cellular levels of the p53 $\beta$ isoform (Figure 2D, Figure S2E, S2F), thus implicating hSMG-1 in this regulation. Since p53 $\beta$ contains a premature stop codon and is vulnerable to NMD degradation, knocking down hSMG- 1 could have induced $\mathrm{p} 53 \beta$ by blocking the NMD pathway. To examine this possibility, we used an alternative approach to blunt the NMD pathway, by knocking down Upf1, a downstream target of hSMG-1 and an effector in the NMD complex that degrades RNA. Upf1 siRNA treatment minimally increased levels of $p 53 \beta$ mRNA and protein levels in the cytoplasm, but had no significant effect on $\mathrm{p} 53 \beta$ mRNA levels in the nuclear fraction (data not shown). Thus, the increase of nuclear $\mathrm{p} 53 \beta \mathrm{mRNA}$ level occurring following reduction of hSMG-1 level appears to be due to enhanced alternative splicing, not decreased degradation of the $\mathrm{p} 53 \beta$ message by the NMD pathway. 
In order to link inhibition of hSMG-1 kinase activity to the regulation of $\mathrm{p} 53 \beta$ seen after IR or CP treatment, we examined the phosphorylation of the endogenous substrate of hSMG-1, Upf1, after these treatments. The PIKK kinases, including hSMG-1, phosphorylate target proteins at S/TQ sites (38-40) and an antibody that specifically recognized phosphorylated S/TQ residues bound to immunoprecipitated Upf1 (Figure 2E and Figure S2G), consistent with basal phosphorylation of Upf1 by a PIKK kinase. Treatment of cells with CP (Figure 2E, left panel), irradiation of cells (Figure 2E, right panel), or knock-down of hSMG-1 with siRNA (Figure S2G) all attenuated Upf1 S/TQ phosphorylation. These results suggest that treatment of cells with IR or CP inhibits the kinase activity of hSMG-1 and promotes the alternative splicing of $\mathrm{p} 53 \beta$.

To explore the mechanism of how hSMG1 interferes with p53 $\beta$ splicing, we investigated interactions between hSMG1 and p53 pre-mRNA. No differences in total hSMG1 binding to p53 pre-mRNA were noted before and after CP treatment using immunoprecipitation of hSMG1 and RT-PCR for bound p53 mRNA (data not shown). However, changes in sitespecific binding of hSMG1 associated with hSMG1 inhibition were found (Figure 2F). Using an RNase-mediated protein footprinting technique $(21,22)$ to fine-map the binding regions of hSMG1 on p53 pre-mRNA, we observed a CP-induced selective eviction of hSMG1 from p53 pre-mRNA at sites between introns 8 and 10 (covering exon 9 and exon $9 \beta$ ). Strikingly, this is exactly where the alternative splicing of $p 53 \beta$ occurs (region B, C, F in Figure 2F). The release of hSMG1 from 553 pre-mRNA post $\mathrm{CP}$ treatment is regulated locally since neither the binding of hSMG1 to more distal regions (region A, J in Figure 2F) nor the global binding of hSMG1 to the bulk p53 pre-mRNA (data not shown) were affected. These results suggest that kinase-competent hSMG1 occupies certain regulatory regions of precursor mRNA and that inactivation of the kinase exposes selected region(s) for factors promoting $\mathrm{p} 53 \beta$ splicing.

\section{RPL26 and SRSF7 positively regulate the splicing of $p 53 \beta$}

We previously implicated RPL26 protein in the regulation of p53 mRNA translation after IR via its direct binding to a $5^{\prime}-3^{\prime}$ UTR interaction region of human p53 mRNA in the nucleus $(5,6)$. Since $p 53 \beta$ and full-length $\mathrm{p} 53 \mathrm{mRNA}$ are transcribed from the same promoter and share the same UTR regions, RPL26 should also have the capacity to bind p53 $\beta$ mRNA. In fact, the increased levels of $p 53 \beta$ mRNA after IR were first noted in an evaluation of the transcriptome bound to RPL26 following IR (Figure S1A), suggesting direct binding of RPL26 to $p 53 \beta$ mRNA.

Supporting a role of RPL26 in the induced alternative splicing of the p53 $\beta$ variant, downregulation of RPL26 strongly suppressed the induced levels of p $53 \beta$ mRNA and protein (Figure 3A, Figure S3A, S3B). With primers designed to detect unspliced p53 pre-mRNA (Figure 1A), the direct binding of RPL26 protein to $\mathrm{p} 53$ pre-mRNA was also confirmed and linked to this regulatory pathway by the observation that down-regulation of hSMG-1 increased the amount of both unspliced p53 pre-mRNA and spliced p53 $\beta$ mRNA in the nuclear anti-RPL26 immunocomplex (Figure 3B, Figure S3C, S3D). Thus, RPL26 contributes to IR-induced and CP-induced increases in p $53 \beta$ levels and directly binds to p53 
pre-mRNA in the nucleus in a manner dependent on inhibition of hSMG-1 and its associated selective release from the exon 9 region of $\mathrm{p} 53$ pre-mRNA.

Though both hSMG-1 and RPL26 appear to regulate alternative splicing of p53 mRNA, neither are splicing factors. While hSMG-1 and RPL26 appear to be transducers of the DNA damage signal to elicit the alternative splicing of p $53 \beta$, there must be a downstream executor of the actual splicing process. Removal of introns from precursor mRNAs is carried out by the spliceosome, a highly dynamic protein-RNA complex (41). The assembly of spliceosomes on precursor mRNAs and the splicing events themselves are tightly regulated. Two families of proteins have been recognized as classic trans-acting splicing regulators: serine/arginine-rich splicing family proteins and heterogeneous nuclear ribonucleoproteins (hnRNPs). Among 12 SR proteins, SRSF3 (SRp20), the smallest family member, has been reported to be a negative regulator of $\mathrm{p} 53 \beta$ splicing and participates in $\mathrm{p} 53 \beta$-dependent replicative senescence (18). In a recent genome-wide siRNA screen, SRSF7 stands out as an important regulator of the alternative splicing of exon 6 of Fas/CD95 and other AS events in genes involved in apoptosis (42). This SR family member has been shown to cooperate with SRSF3 for the alternative exon splicing of CD44 and transport of viral RNAs (43) and altered expression of SRSF7 is associated with renal cancer (44). Knockdown of SRSF3 in MCF-7 cells actually increased basal p53 $\beta$ levels (Figure S4A), while SRSF7 knockdown reduced both basal and induced p53 $\beta$ levels (Figure 4A, Figure S4B). Thus, SRSF7 appears to be the splicing factor involved in damage induction of p53 $\beta$. Since SRSF7 siRNA had no effect on the basal splicing of the full-length p53 message (Figure S4C), it seems that the alternative splicing of $\mathrm{p} 53 \beta$ is a specific process mediated by SRSF7.

The splicing activity of SRSF7 is subject to iron regulation through its Zinc Knuckle domain (42). Intracellular iron inhibits the binding of SRSF7 to Fas/CD95 mRNA and results in the exon 6 inclusion. Consistent with a role for this iron-dependent enzyme in alternative splicing of p53, decreasing intracellular iron levels by treatment with the iron chelator DFO suppressed $p 53 \beta$ splicing and elevating iron levels by treatment of cell with Hemin, enhanced it (Figure 4B, Figure S4D). IR treatment had no effect on SRSF7 protein levels or intracellular distribution (data not shown), but IR treatment did increase the binding of SRSF7 to p53 pre-mRNA (Figure 4C). Further, a fraction of SRSF7 protein binds to RPL26 protein independent of RNA (Figure S4E). As expected, this interaction is more easily detected in the nucleus than in the cytoplasm (Figure 4D) since majority of SRSF7 locates in the nuclei. No interactions between RPL26 and SRSF3 were noted (data not shown). Importantly, siRNA knock-down of RPL26 blunted the binding of SRSF7 to precursor p53 mRNA (Figure 4E), demonstrating a functional role for RPL26 in the recruitment of SRSF7 to p53 mRNA (Figure S4F).

\section{Alternative splicing induced by other types of DNA damage}

To assess whether DNA damaging agents other than IR could also activate this alternative splicing pathway, we treated cells with either MMS or UV irradiation. Similar to the cellular responses seen with IR treatment, exposure to the base-damaging agent, MMS, induced a rapid induction of both p53 $\beta$ mRNA and protein and this induction was dependent on both RPL26 and SRSF7 (Figure S4G). In contrast, while UV irradiation also induced RPL26- 
dependent alternative splicing of $\mathrm{p} 53$, the $\Delta$ isoform of $\mathrm{p} 53$ was induced, not the $\beta$ isoform (Figure S4H, S4I). Thus, different types of DNA damage appear to regulate splicing differently.

\section{Induction of alternatively spliced $p 53 \beta$ contributes to IR-induced cellular senescence}

Previous reports have suggested that the $\beta$ isoform of $p 53$ contributes to replicative senescence in lymphocytes and fibroblasts $(15,16)$. A genetically manipulated mouse expressing a 553 protein lacking the carboxyl terminus, similar to the human p $53 \beta$ protein, exhibits deregulated telomere metabolism and premature senescence (45) and overexpression of human $\mathrm{p} 53 \beta$ induces apoptosis or cellular senescence in different systems $(15,17,46)$. Consistent with these observations, we found that overexpression of human p53 $\beta$ increased markers of cellular senescence in a variety of human tumor cell lines (MCF-7, A549, HCT116), including enlarged cell size, decreased cell proliferation, and elevated senescence-associated $\beta$-galactosidase (SA- $\beta$-gal) activity (Figure 5A, Figure S5A), but had no effect on apoptosis (Figure S5B). Introduction of an R175H hotspot mutation in the $\mathrm{p} 53 \beta \mathrm{cDNA}$, which impairs the ability of full-length $\mathrm{p} 53$ protein to bind DNA (47), abolished p53 $\beta$-dependent growth arrest and SA- $\beta$-gal activity (Figure 5A), suggesting that the induction of senescence characteristics by p $53 \beta$ requires its ability to bind to DNA, and presumably its ability to affect transcription. Notably, overexpression of p53 $\beta$ failed to induce growth arrest, senescence associated $\beta$-galactosidase activity, or apoptosis in cells lacking endogenous p53 genes (p53-null HCT116 and H1299; Figure S5B, S5C and data not shown). However, we could not detect significant binding between $p 53 \beta$ and full length $p 53$ proteins (Figure S5D), suggesting that any functional interaction of $\mathrm{p} 53 \beta$ and full-length $\mathrm{p} 53$ proteins is not through a physical interaction, but rather via collaborative effects of these two proteins on transcriptional regulation. Consistent with this suggestion, characterization of p53 target gene profiles regulated by p53 $\beta$ expression revealed three groups of differentially regulated genes: group I, regulated by p53 $\beta$ independent of full-length p53 status (e.g. p21, TP53INPI etc.); group II, regulated by p53 $\beta$, but dependent on the presence of full-length p53 (e.g. GDF15, ADAMTS7); and group III, not regulated by p53 $\beta$ (Figure S5E). Thus, the induction of alternatively spliced $p 53 \beta$ has the potential to interfere with regulation of the p53 network and alter cellular responses to DNA damage and other stresses.

In order to more effectively investigate the functional roles of $p 53 \beta$ in response to DNA damage, we utilized CRISPR-Cas9 gene editing to specifically knock out $\mathrm{p} 53 \beta$ without affecting full-length $\mathrm{p} 53$ expression and induction. We established two p $53 \beta$ CRISPR clones that lost expression of $\mathrm{p} 53 \beta$ mRNA due to a deletion of the branch site adenine (A) upstream of the polypyrimidine tract and the $3^{\prime}$ acceptor site within the intron 9 region of the p53 gene required for $\beta$ splicing (Figure 5B, Figure S5F). While treatment of these mutated cells with IR, CP, or hSMG-1 siRNA could no longer induce p53 $\beta$ in these cells (Figure 5B), neither cellular proliferation (Figure S5G, left) nor the induction of full-length p53 and p53dependent transactivation of p21 by IR (Figure S5G, right panel) were affected. In contrast, IR induction of the cellular senescence markers, SA- $\beta$-galactosidase activity (Figure 5C, Figure S6A) as well as markers of the senescence associated secretory phenotype (SASP) (Figure S6B), were significantly reduced in the p53 $\beta$-knockout cells and p $53 \beta$ knock down cells (Figure S6A, right graph). Further, modulation of the "hSMG-1-RPL26-SRSF7" 
pathway required for IR-induced p53 $\beta$ alternative splicing also affected cellular senescence markers as well. Knock-down of hSMG-1, which activates this splicing pathway, increased the percentage of SA- $\beta$-galactosidase positive cells (Figure 5D, Figure S6C left graph) and knock-down of SRSF7, a positive splicing factor for $\mathrm{p} 53 \beta$, suppressed IR-induced SA- $\beta$ galactosidase induction (Figure 5E, Figure S6C right graph). Thus, modulation of multiple steps in this alternative splicing pathway, hSMG1, SRSF7, and p53 $\beta$, all impact on IR induction of cellular senescence markers.

To begin to clarify the mechanisms by which $\mathrm{p} 53 \beta$ contributes to IR-induced senescence, we utilized a human whole transcriptome array to compare the global gene expression profiles of control and p53 $\beta$ CRISPR knockout clones before and after IR. Control cells and p53 $\beta$ CRISPR knockout cells differentially expressed 72 genes and 103 genes (with a fold change 22), respectively, four hours after IR (Figure S6D). Among these genes, 43 genes changed exclusively in the irradiated p $53 \beta$ CRISPR knockout clones (mainly upregulated) and 14 unique genes changed in control group (Figure S6D). Gene ontology analyses (Table S1) revealed common IR-induced pathways in the control vs. p53 $\beta$ CRISPR knockout cells, such as "thymocyte apoptotic process (GO: 0070242)" and "neutrophil activation involved in immune response (GO: 0002283)". On the other hand, the "negative regulation of cell aging (GO: 0090344)" pathway with BCL6 (B-Cell CLL/Lymphoma 6), SIRT1 (Sirtuin 1) were suppressed in control cells after IR, but not in the p53 $\beta$ CRISPR knockout cells (Figure $5 \mathrm{~F}$, top). The failure of the $533 \beta$ CRISPR knockout cells to repress these gene products after IR was specifically validated in separate experiments (Figure 5F, bottom). These observations suggest that $\mathrm{p} 53 \beta$ may regulate IR-induced senescence by repressing negative regulators of aging. Together, these data imply that $\mathrm{p} 53 \beta$ may link more closely to DNA damage-induced senescence than other p53-dependent phenotypes, such as damage-induced apoptosis and growth arrest.

\section{The "hSMG-1-RPL26-SRSF7" pathway controls alternative splicing of multiple gene products after IR}

To ask whether the "hSMG-1-RPL26-SRSF7" pathway induced alternative splicing of gene products other than $\mathrm{p} 53$, we analyzed the microarray data at an exon level for IR-induced alternatively spliced RNAs. 607 alternative splice events were noted in IR-treated cells with no significant change of the transcription of those genes. The top and bottom 20 alternative splice events were ranked by the value of their splicing index (Table S2) and we chose to validate two of these events, CDYL (Chromodomain protein, Y like) and SMAD3 (SMAD family member 3) (Figure 6A). In contrast to the intron retention and premature stop codon required to generate $\mathrm{p} 53 \beta$, the CDYL splice variants were generated by differential exon usage. The CDYL970 variant shares a 3' sequence with CDYL4824 (major form), but includes an alternative first exon. To confirm that the "hSMG-1-RPL26-SRSF7" pathway was involved in IR-induced alternative splicing of CDYL, we treated cells with siRNAs of hSMG-1 or SRSF7. Reduction of hSMG-1 specifically increased levels of CDYL970 isoform (Figure 6B), thus recapitulating the splicing of CDYL observed in IR-treated cells (Figure 6A, left). Reduction of SRSF7 expression mildly repressed the basal level of CDYL970 splice variant and significantly repressed the IR-induced alternative splice form 
(Figure 6C). This was a specific effect on this splice variant as another alternative splice form, CDYL4824, was not affected in the same ways.

\section{DISCUSSION}

We identified a new signaling pathway that regulates the alternative splicing of p53 and other mRNA species in response to genotoxic damage and participates in the regulation of radiation-induced cellular senescence markers (Figure 6D, Figure S4F). Ionizing radiation inhibits the activity of the PIKK family kinase, hSMG1, releasing it from the exon 9 region of p53 pre-mRNA, which leads to the binding of RPL26 protein to p53 pre-mRNA and recruitment of the RNA splicing factor, SRSF7. All of these steps are required for increased expression of $\mathrm{p} 53 \beta \mathrm{mRNA}$ and protein after IR and also appear to regulate the alternative splicing of other gene products as well. Similar cellular responses are seen after cellular exposure to the base-damaging agent, MMS. Inhibition of these pathway steps, including specific knockout of the $\beta$ isoform of $p 53$, significantly blunts cellular senescence markers induced by irradiation. The regulation of cellular senescence by p $53 \beta$ requires its ability to bind to DNA, appears to depend on functional interplay between the alternatively spliced p53 protein and full-length $\mathrm{p} 53$ protein, and is associated with transcriptional repression of select gene products involved in regulation of cellular aging, such as BCL6 and SIRT1. Therapeutic irradiation has numerous side effects, including induction of tissue fibrosis, cellular senescence, and aging phenotypes (48-50). The model pathway reported here suggests that suppression of p $53 \beta$ induction or activity could mitigate some of these toxicities. Future studies in vivo could explore these possibilities.

\section{Roles of hSMG1, RPL26, and SRSF7}

In unstressed cells, $p 53 \beta$ mRNA levels are kept low by two mechanisms: one is tightly regulated alternative splicing of $\mathrm{p} 53 \beta$ by kinase-competent hSMG1, which occupies the regions of $\mathrm{p} 53$ pre-mRNA required for $\mathrm{p} 53 \beta$ splicing and prevents the access of positive splicing regulators (i.e. RPL26 and SRSF7) to the unspliced message (Figure 2-4, model in Figure S4F). In addition to limited production of $p 53 \beta$ mRNA due to suppression of its splicing, the retention of exon9 $\beta$ in $553 \beta$ mRNA introduces a premature stop codon that would activate the NMD pathway for its rapid degradation. Since hSMG1 is also a critical kinase for NMD pathway, these two mechanisms both rely on the kinase activity of hSMG1, but differ in location. While splicing events occur inside nuclei and most RNA decay pathways act in the cytosol, there are some reports suggesting that NMD degradation can take place in the nuclei, depending on the nature of the mRNA $(51,52)$. We noted that nuclear p $53 \beta$ mRNA levels are around 5-fold higher than its levels in the cytoplasm (data not shown), suggesting that any NMD which might occur in the nucleus is likely far less efficient at degrading p53 $\beta$ message than cytoplasmic NMD and supports the focus on interactions of the various pathway components in the nuclear fraction of cells.

In contrast to the activation of other PIKK kinases, including ATM, ATR, and DNA-PK, that occurs after genotoxic stress $(1,37,53)$, hSMG1 kinase activity appears to be blunted at early time points after IR (Figure 2E). The inhibition of hSMG1 activity after IR or CP treatment leads to local eviction of hSMG1 protein from $\mathrm{p} 53$ precursor mRNA and allows 
binding of RPL26 protein to p53 precursor mRNA, an interaction that facilitates recruitment of SRSF7 to promote the alternative splicing of p53. Both RPL26 and SRSF7 bind to p53 pre-mRNA, which is only present in the nucleus (Figures 3B, Figure 4C, Figure 4E), similar to our previous observations demonstrating the role of RPL26 in regulating p53 translation after DNA damage by binding to mature p53 mRNA in the nucleus $(5,6)$. RPL26 is also an integral ribosomal protein involved in rRNA processing in the nucleoli and general translation in the cytoplasm. However, since a pioneer round of translation is required for eliciting NMD of mRNAs containing premature termination codons $(33,34)$, if RPL26 were affecting levels of p $53 \beta$ mRNA through regulation of this initial translation step as a component of ribosomes, then knocking down RPL26 should stabilize p53 $\beta$ mRNA instead of inhibiting $\mathrm{p} 53 \beta$ synthesis. Thus, like regulation of DNA damage-induced $\mathrm{p} 53$ protein translation $(5,6,54)$, multiple lines of evidence suggest that the regulation of $\mathrm{p} 53 \beta$ levels is an extra-ribosomal activity of RPL26.

While we have not yet fully characterized the molecular mechanisms involved in the p53 RNA splicing events, the iron-dependent SRSF7 splicing regulator is clearly involved. We demonstrated that SRSF7 interacts with RPL26 protein, that the binding of SRSF7 to p53 pre-mRNA requires RPL26, and that SRSF7 down-regulation blunts CP- and IR-induction of p53 $\beta$ (Figure 4, Figure S4). In contrast, SRSF3 down-regulation has the opposite effect and actually increases levels of p53 $\beta$ (Figure S4A), which is consistent with previous reports (18). SRSF7 is an iron-dependent splicing factor and $\mathrm{p} 53 \beta$ expression was reduced by iron chelation and enhanced by iron elevation (Figure 4B, Figure S4D). We suspect that the general RNA binding activity of SRSF7 is not directly altered by iron since the enzyme contains a highly conserved RNA Recognition Motif (RRM) whose function is independent of iron (42), but rather that iron is altering the binding preferences of SRSF7 to a different subset of mRNAs and facilitating select alternative splicing events.

\section{p53 splice variants and cellular outcomes}

Over $90 \%$ of human genes have at least $2-3$ alternative splice variants $(7,55)$. Nine different transcripts are derived by splicing p53 precursor mRNA, encoding for 12 different proteins. p53 is a central mediator of cellular stress responses, but stress regulation of p53 is largely post-transcriptional (56) and cellular effects have largely been attributed to functions of the full-length protein. However, there have been some suggestions that temporal or spatial expression of $\mathrm{p} 53$ protein variants might also contribute to cellular outcomes during p53dependent stress responses. Consistent with prior suggestions that $\mathrm{p} 53 \beta$ may participate in the senescence process either caused by exhaustion of replication capacity (replicative senescence) or stress-induced premature senescence $(15,16)$, we found that the induction of p53 $\beta$ contributes to IR-induced cellular senescence. While specific deletion of p53 $\beta$ does not interfere with cell growth, DNA damage signaling (Figure S5G), or p53-dependent induction of genes involved in apoptosis or inflammatory responses (Figure S5B, Table S1), its deletion does relieve both IR-induction of senescence markers and IR-repression of certain negative regulators of cell aging (Figure $5 \mathrm{~F}$ ). We validated two such p $53 \beta$ targets, BCL6 and SIRT1, both of which are epigenetic transcriptional repressors, suggesting that p53 $\beta$ may influence IR-induced senescence via chromatin effects. Interestingly, in contrast to the BCL6 repression seen with $\mathrm{p} 53 \beta$ expression, full-length $\mathrm{p} 53$ promotes BCL6 
transcription (57). Since we noted that $\mathrm{p} 53 \beta$ only induced senescence in the presence of an endogenous p53 allele (Figure S5C), these observations further support the concept that $\mathrm{p} 53 \beta$ induction is altering the $\mathrm{p} 53$ target profile.

\section{DNA damage induced alternative splicing}

It seemed unlikely that the "hSMG-1-RPL26-SRSF7" pathway exists to regulate the alternative splicing of just $\mathrm{p} 53$. In fact, changes in hundreds of alternative splice products were noted after IR exposure (Table S2). We validated IR-induced alternative splice changes in two of these gene products, CDYL and SMAD3, and demonstrated that CDYL regulation is also modulated by hSMG1 and SRSF7 (Figure 6). The functional roles of these alternative gene products in IR responses have not yet been elucidated. Thus, this pathway appears to be a general modulator of alternative splicing after IR or MMS treatment. Kornblihtt and colleagues previously reported changes in alternative splicing of Bcl-x induced by UV irradiation in a p53-independent manner, a process that was dependent on inhibition of RNA polymerase II elongation (11). While we did not observe induction of p53 $\beta$ after UV irradiation, induction of the $\Delta$ isoform of p53 was noted after $\mathrm{UV}$ exposure (Figure $\mathrm{S} 4 \mathrm{H}$ ). Thus, DNA damage induction of alternative splicing events may be a general phenomenon, but the exact mechanisms involved and which specific alternative gene products are induced appears to vary between different types of damage or stress. Future studies will be needed to characterize splicing pathways induced by different types of damage or stress and the functional roles of the alternatively spliced products. A virtually unlimited repertoire of novel gene products can be created by alternative splicing pathways. Thus, it now appears clear that DNA damage signaling pathways have the capacity to modulate gene expression beyond regulation of translation or transcription.

\section{METHODS}

\section{Cell culture, stable cell line and transfection}

MCF7, A549, H1299, HCT116 cells were maintained in DMEM plus 10\% FBS and 1\% antibiotics. SY5Y cells, both control and ATM CRISPR-knockout, were maintained in RPMI supplemented with 15\% FBS plus $1 \%$ antibiotics. Human adult fibroblastPCS-201-012 ${ }^{\mathrm{TM}}$ was purchased from ATCC and cultured in the same medium. MCF-7,

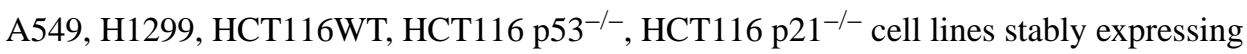
Flag tagged $\mathrm{p} 53 \beta$, p $53 \beta \mathrm{R} 175 \mathrm{H}$, or GFP tagged $\mathrm{p} 53 \beta$ were generated by infection of lentiviruses and selected with $2 \mathrm{ug} / \mathrm{ml}$ of puromycin. After selection, stable lines were maintained in DMEM plus 10\% FBS supplemented with $1 \mathrm{ug} / \mathrm{ml}$ of puromycin. $4 \mathrm{nM}$ siRNA duplexes were transfected into cells using Lipofectamine RNAiMAX (Invitrogen). MCF-7 (date of purchase, 4/18/2006), SY5Y (2/12/1999), A549 (2/7/2006), H1299 (3/24/2000), HCT116WT (2/1/2003), HCT116 p53-/- (5/1/2009), HCT116 p21-/- (11/14/2005) were purchased from ATCC between year 1999 and 2009 and authenticated on Aug 292016 when the manuscript was under review using certified human cell line authentication (CLA) analysis provided by Duke University DNA analysis facility. 


\section{Plasmids, chemicals and siRNAs}

Plasmids used in this study for viral packaging and generation of stable lines include pLenti-

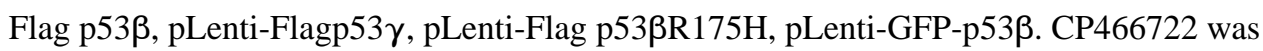
synthesized in the Chemical Biology Department at St Jude Children's Research Hospital (20). Deferoxamine (DFO) (Cat\#D9533) and Hemin (Cat\#H9039) were purchased from Sigma. All chemicals were dissolved in DMSO. siRNA duplexes were designed and synthesized by Sigma. Their sequences are listed in Table S3. ATMsi RNA (human ATM ON-TARGET plus SMARTpool) and Chk2siRNA (human CHEK2 siGENOME SMARTpool) were purchased from Thermo Scientific Dharmacom.

\section{RNase-mediated protein footprint and IP-RT-PCR}

The RNase mediated protein footprint protocol was adopted from $(21,22)$. In brief, MCF7 cells in $15 \mathrm{~cm}$ dish with $80 \%$ confluence were fixed with $1 \%$ final concentration of formaldehyde at room temperature for 10 minutes with shaking. A final concentration of $125 \mathrm{mM}$ glycine was then added drop-wise for additional 5 minutes incubation. Then, cells were washed twice with ice cold PBS and collected. Cell pellets were lysed in lysis buffer as described in (6). hSMG1 protein was immunoprecipitated from cell lysate using appropriate

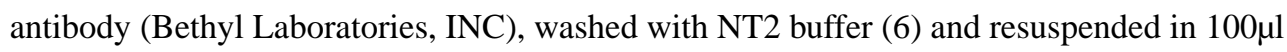
$1 \mathrm{X}$ RNaseONE digestion buffer followed by $100 \mathrm{U} / \mathrm{ml}$ RNaseONE digestion (Promega) with $200 \mu \mathrm{g} / \mathrm{ml} \mathrm{BSA}$ for $1 \mathrm{hr}$ at room temperature. The proteins were then denatured and digested by $1 \%$ SDS and $0.1 \mathrm{mg} / \mathrm{ml}$ proteinase $\mathrm{K}$ (Roche) for 15 minutes at room temperature before $2 \mathrm{hr}$ incubation at $65^{\circ} \mathrm{C}$ for reverse crosslinking. After reverse crosslinking, digested RNA was extracted by phenol-chloroform for real time RT-PCR as described below. IP-RT-PCR reaction was performed without crosslink and RNase digestion as described in (6).

\section{Immunoblot, immunoprecipitation, co-immunoprecipitation}

Cell lysates were prepared by a freeze-thaw followed by incubation in RIPA buffer for 30 minutes on ice and the supernatants were analyzed by immunoblot analysis or immunoprecipitation. For immunoblot analysis, $20-50 \mu \mathrm{g}$ protein samples were denatured in equal volume of SDS sample buffer (BioRad), separated by 4-12\% SDS-PAGE and transferred to nitrocellulose membrane. The blots were probed with primary antibody against p53 (DO-1; Santa Cruz Biotechnology), nucleolin (MS-3; Santa Cruz Biotechnology), PARP, pSQ/TQ (Cell Signaling technology), RPL26, Upf1, hSMG-1, SRSF7 (Bethyl Laboratories, INC), LDH (Abcam), ATM (23), Chk2 (Santa Cruz Biotechnology), SRSF3 (Life technology), p21 (BD Pharmingen). Primary antibody binding was detected by incubating with horseradish peroxidase (HRP)-conjugated anti-rabbit, anti-mouse secondary antibody followed by enhanced chemiluminescent visualization (ECL) system (Amersham Biosciences, Buckinghamshire, UK). For immunoprecipitation of Upf1, $1 \mathrm{mg}$ whole cell extract in RIPA buffer (6) was cleared by protein A/G-PLUS agarose beads (Calbiochem, Rockland, Inc) and rabbit IgG (Sigma-Aldrich). Precleared lysates were incubated with anti-Upf1 antibody (Bethyl Laboratories, INC). Immunoprecipitated proteins were then washed extensively with lysis buffer and subjected to Western blot analysis as described above. For co- 
immunoprecipitations, cells were lysed in TGN buffer (6) and the rest of the procedure followed the immunoprecipitation protocol.

\section{Real-time RT-PCR}

$1 \mu \mathrm{g}$ of RNA prepared using Trizol reagent (Invitrogen) was treated with DNase I (Invitrogen) and then reverse transcribed following high capacity cDNA reverse transcription kit instruction manual (ABI). Real-time PCR was performed using StepOne plus real time PCR system (ABI). The reaction was performed in triplicate using FastStart Universal SYBR Green Master reagents (Roche). PCR condition was $95^{\circ} \mathrm{C} 10^{\prime}$ (denature) followed by 40 cycles of $95^{\circ} \mathrm{C} 3^{\prime \prime}, 60^{\circ} \mathrm{C}$ or $56^{\circ} \mathrm{C} 30^{\prime \prime}$ for amplification and $95^{\circ} \mathrm{C} 15^{\prime \prime}, 60^{\circ} \mathrm{C} 1^{\prime}$ for melting curve. mRNA level was calculated using the $\Delta \Delta C \mathrm{C}$ method and normalized to GAPDH expression level. Primer sequences for qPCR are listed in Table S3.

\section{Flow SA- $\beta$-galactosidase assay and SA- $\beta$-galactosidase staining}

Flow SA- $\beta$-galactosidase assay was adopted from (24). In brief, subconfluent cells were first treated with $100 \mathrm{nM}$ bafilomycin A1 (Sigma) for $1 \mathrm{~h}$ in fresh DMEM plus 10\% FBS and 1\% antibiotics medium at $37^{\circ} \mathrm{C}, 5 \% \mathrm{CO}_{2}$. A final concentration of $33 \mu \mathrm{M} \mathrm{C}_{12} \mathrm{FDG}$ (Setareh Biotech, LLC) was added to the medium for an extra $2 \mathrm{hr}$ incubation. The cell monolayer was then washed twice with room temperature PBS and harvested by trypsinization followed by centrifugation at $200 \mathrm{~g}$ for $10^{\prime}$ at $4{ }^{\circ} \mathrm{C}$. Cells were resuspended in ice-cold PBS at a concentration of $1 \times 10^{6}$ cells $/ \mathrm{ml}$ and run immediately on BDCalibar. Data was collected and analyzed using CellQuest following the instructions of manufactur's manual. SA- $\beta$ galactosidase staining was performed following the protocol provided by Senescence $\beta$ galactosidase cell staining kit (Cell Signaling technology). Stained cells were maintained in appropriate amount of $70 \%$ glycerol and subjected to microscopy.

\section{Generation of $p 53 \beta$ CRISPR knock out cells}

To knock out p53 $\beta$, guide RNA (gRNA) targeting p53 $\beta$ (Forward:

5'CACCGATATATATTATGGTATAAGT; Reverse:

5 'AAACACTTATACCATAATATATATC) was designed and cloned into lentiCRISPRv2 plasmid for viral packaging. MCF7 cells were infected with the viruses and selected by $2 \mu \mathrm{g} / \mathrm{ml}$ puromycin for 2 days followed by 14 day maintenance in $1^{\prime} \mathrm{g} / \mathrm{ml}$ puromycin. The stable $\mathrm{p} 53 \beta$ CRISPR knockout clones undergo serial dilution for single cell separation. The individual $\mathrm{p} 53 \beta$ CRISPR knockout cells were expanded in puromycin free DMEM medium supplemented with 10\% FBS and 1\% antibiotics. Finally, the DNA was extracted from these clones and the region surrounding Cas9 cutting site was PCR amplified for sequencing.

\section{Microarray}

Total RNAs of two control cells and two p53 $\beta$ CRISPR knockout clones in triplicate without any treatment or 4 hour after 20 gy irradiation were extracted using RNeasy mini kit (Qiagen) and treated with DNAse I (Life technology). The mRNA samples were assayed using the Affymetrix GeneChip Human Transcriptome Array 2.0 platform at the Sequencing and Genomic Technologies Shared Resource of the Duke Cancer Institute. The resulting arrays were pre-processed using the RMA (Robust Multichip Average) algorithm (25), 
followed by quantile normalization at the probe $(n=925,032)$ and gene $(n=70,523)$ level using the rma function in the $\mathrm{R}$ (26) extension package affy (27). The annotation and library files were downloaded from Affymetrix website (release 35.2). The Transcriptome Analysis Console (TAC) 3.0 software was employed for alternative splicing analysis using Affymetrix recommended filter criteria and algorithm options (28). The alternative splicing index was calculated as:

$$
\text { splicing index }=\frac{\frac{\operatorname{Exon}_{i j}^{(1)}}{\operatorname{Gene_{i}^{(1)}}}}{\frac{\operatorname{Exon}_{i j}^{(0)}}{G e n e_{i}^{(0)}}}
$$

for gene $i$ and exon $j$ without IR (condition (0)) or with IR (condition (1)). To account for multiple testing, False-discovery rate (FDR) adjusted $p$-values were computed using Benjamini-Hochberg method (29). Gene pathway analyses were conducted using a resampling-based method implemented by the R extension package safe (30) using Gene Ontology categories (31). Microarray data have been deposited to GEO database with an accession number GSE84813.

\section{Supplementary Material}

Refer to Web version on PubMed Central for supplementary material.

\section{Acknowledgments}

We would like to thank the Duke Sequencing and Genomic Technologies Core facility (a Duke Cancer Institute CCSG and a Duke Genomic and Computational Biology shared resource facility) for their technical support, microarray data management and feedback on the generation of the microarray data reported in this manuscript. We also thank Dr. Donald Fleenor for outstanding technical support and members of the Kastan lab for ideas and manuscript review.

\section{GRANT SUPPORT}

This work was supported by grants R01ES005777 and P30CA014236 from the National Institutes of Health.

\section{References}

1. Kastan MB, Bartek J. Cell-cycle checkpoints and cancer. Nature. 2004; 432:316-23. [PubMed: 15549093]

2. Campisi J. Aging, cellular senescence, and cancer. Annu Rev Physiol. 2013; 75:685-705. [PubMed: 23140366]

3. Haupt Y, Maya R, Kazaz A, Oren M. Mdm2 promotes the rapid degradation of p53. Nature. 1997; 387:296-9. [PubMed: 9153395]

4. Kubbutat MH, Jones SN, Vousden KH. Regulation of p53 stability by Mdm2. Nature. 1997; 387:299-303. [PubMed: 9153396]

5. Chen J, Kastan MB. $5^{\prime}-3^{\prime}$-UTR interactions regulate p53 mRNA translation and provide a target for modulating p53 induction after DNA damage. Genes Dev. 2010; 24:2146-56. [PubMed: 20837656]

6. Takagi M, Absalon MJ, McLure KG, Kastan MB. Regulation of p53 translation and induction after DNA damage by ribosomal protein L26 and nucleolin. Cell. 2005; 123:49-63. [PubMed: 16213212]

7. Keren H, Lev-Maor G, Ast G. Alternative splicing and evolution: diversification, exon definition and function. Nat Rev Genet. 2010; 11:345-55. [PubMed: 20376054] 
8. Nilsen TW, Graveley BR. Expansion of the eukaryotic proteome by alternative splicing. Nature. 2010; 463:457-63. [PubMed: 20110989]

9. Scotti MM, Swanson MS. RNA mis-splicing in disease. Nat Rev Genet. 2016; 17:19-32. [PubMed: 26593421]

10. Faustino NA, Cooper TA. Pre-mRNA splicing and human disease. Genes Dev. 2003; 17:419-37. [PubMed: 12600935]

11. Munoz MJ, Perez Santangelo MS, Paronetto MP, de la Mata M, Pelisch F, Boireau S, et al. DNA damage regulates alternative splicing through inhibition of RNA polymerase II elongation. Cell. 2009; 137:708-20. [PubMed: 19450518]

12. Bourdon JC. p53 isoforms change p53 paradigm. Mol Cell Oncol. 2014; 1:e969136. [PubMed: 27308370]

13. Mills AA. p53: link to the past, bridge to the future. Genes Dev. 2005; 19:2091-9. [PubMed: 16166374]

14. Khoury MP, Bourdon JC. p53 Isoforms: An Intracellular Microprocessor? Genes Cancer. 2011; 2:453-65. [PubMed: 21779513]

15. Fujita K, Mondal AM, Horikawa I, Nguyen GH, Kumamoto K, Sohn JJ, et al. p53 isoforms Delta133p53 and p53beta are endogenous regulators of replicative cellular senescence. Nat Cell Biol. 2009; 11:1135-42. [PubMed: 19701195]

16. Mondal AM, Horikawa I, Pine SR, Fujita K, Morgan KM, Vera E, et al. p53 isoforms regulate aging- and tumor-associated replicative senescence in T lymphocytes. J Clin Invest. 2013; 123:5247-57. [PubMed: 24231352]

17. Graupner V, Schulze-Osthoff K, Essmann F, Janicke RU. Functional characterization of p53beta and p53gamma, two isoforms of the tumor suppressor p53. Cell Cycle. 2009; 8:1238-48. [PubMed: 19305147]

18. Tang Y, Horikawa I, Ajiro M, Robles AI, Fujita K, Mondal AM, et al. Downregulation of splicing factor SRSF3 induces p53beta, an alternatively spliced isoform of p53 that promotes cellular senescence. Oncogene. 2013; 32:2792-8. [PubMed: 22777358]

19. Marcel V, Dichtel-Danjoy ML, Sagne C, Hafsi H, Ma D, Ortiz-Cuaran S, et al. Biological functions of p53 isoforms through evolution: lessons from animal and cellular models. Cell Death Differ. 2011; 18:1815-24. [PubMed: 21941372]

20. Guo K, Shelat AA, Guy RK, Kastan MB. Development of a cell-based, high-throughput screening assay for ATM kinase inhibitors. J Biomol Screen. 2014; 19:538-46. [PubMed: 24464432]

21. Silverman IM, Li F, Alexander A, Goff L, Trapnell C, Rinn JL, et al. RNase-mediated protein footprint sequencing reveals protein-binding sites throughout the human transcriptome. Genome Biol. 2014; 15:R3. [PubMed: 24393486]

22. Moore MJ, Zhang C, Gantman EC, Mele A, Darnell JC, Darnell RB. Mapping Argonaute and conventional RNA-binding protein interactions with RNA at single-nucleotide resolution using HITS-CLIP and CIMS analysis. Nat Protoc. 2014; 9:263-93. [PubMed: 24407355]

23. Rainey MD, Charlton ME, Stanton RV, Kastan MB. Transient inhibition of ATM kinase is sufficient to enhance cellular sensitivity to ionizing radiation. Cancer Res. 2008; 68:7466-74. [PubMed: 18794134]

24. Debacq-Chainiaux F, Erusalimsky JD, Campisi J, Toussaint O. Protocols to detect senescenceassociated beta-galactosidase (SA-betagal) activity, a biomarker of senescent cells in culture and in vivo. Nat Protoc. 2009; 4:1798-806. [PubMed: 20010931]

25. Irizarry RA, Hobbs B, Collin F, Beazer-Barclay YD, Antonellis KJ, Scherf U, et al. Exploration, normalization, and summaries of high density oligonucleotide array probe level data. Biostatistics. 2003; 4:249-64. [PubMed: 12925520]

26. R Core Team. R: A language and environment for statistical computing. Vienna, Austria: R Foundation for Statistical Computing; 2016.

27. Gautier L, Cope L, Bolstad BM, Irizarry RA. affy--analysis of Affymetrix GeneChip data at the probe level. Bioinformatics. 2004; 20:307-15. [PubMed: 14960456]

28. Transcriptome Analysis Console (TAC) 302014. Affymetrix User Guide. Alternative Splicing Analysis; p. 20-61. 
29. Benjamini Y, Hochberg Y. Controlling the False Discovery Rate - a Practical and Powerful Approach to Multiple Testing. J Roy Stat Soc B Met. 1995; 57:289-300.

30. Barry WT, Nobel AB, Wright FA. Significance analysis of functional categories in gene expression studies: a structured permutation approach. Bioinformatics. 2005; 21:1943-9. [PubMed: 15647293]

31. Carlson, M. GO.db: A set of annotation maps describing the entire Gene Ontology. R package version 3.2.2

32. Ofir-Rosenfeld Y, Boggs K, Michael D, Kastan MB, Oren M. Mdm2 regulates p53 mRNA translation through inhibitory interactions with ribosomal protein L26. Mol Cell. 2008; 32:180-9. [PubMed: 18951086]

33. Kervestin S, Jacobson A. NMD: a multifaceted response to premature translational termination. Nat Rev Mol Cell Biol. 2012; 13:700-12. [PubMed: 23072888]

34. Lykke-Andersen S, Jensen TH. Nonsense-mediated mRNA decay: an intricate machinery that shapes transcriptomes. Nat Rev Mol Cell Biol. 2015; 16:665-77. [PubMed: 26397022]

35. Joruiz SM, Bourdon JC. p53 Isoforms: Key Regulators of the Cell Fate Decision. Cold Spring Harb Perspect Med. 2016; 6(8):1-20.

36. Canman CE, Lim DS, Cimprich KA, Taya Y, Tamai K, Sakaguchi K, et al. Activation of the ATM kinase by ionizing radiation and phosphorylation of p53. Science. 1998; 281:1677-9. [PubMed: 9733515]

37. Abraham RT. PI 3-kinase related kinases: 'big' players in stress-induced signaling pathways. DNA Repair (Amst). 2004; 3:883-7. [PubMed: 15279773]

38. Yamashita A, Ohnishi T, Kashima I, Taya Y, Ohno S. Human SMG-1, a novel phosphatidylinositol 3-kinase-related protein kinase, associates with components of the mRNA surveillance complex and is involved in the regulation of nonsense-mediated mRNA decay. Genes Dev. 2001; 15:221528. [PubMed: 11544179]

39. Kim ST, Lim DS, Canman CE, Kastan MB. Substrate specificities and identification of putative substrates of ATM kinase family members. J Biol Chem. 1999; 274:37538-43. [PubMed: 10608806]

40. Kastan MB, Lim DS. The many substrates and functions of ATM. Nat Rev Mol Cell Biol. 2000; 1:179-86. [PubMed: 11252893]

41. Wahl MC, Will CL, Luhrmann R. The spliceosome: design principles of a dynamic RNP machine. Cell. 2009; 136:701-18. [PubMed: 19239890]

42. Tejedor JR, Papasaikas P, Valcarcel J. Genome-wide identification of Fas/CD95 alternative splicing regulators reveals links with iron homeostasis. Mol Cell. 2015; 57:23-38. [PubMed: 25482508]

43. Muller-McNicoll M, Botti V, de Jesus Domingues AM, Brandl H, Schwich OD, Steiner MC, et al. SR proteins are NXF1 adaptors that link alternative RNA processing to mRNA export. Genes Dev. 2016; 30:553-66. [PubMed: 26944680]

44. Piekielko-Witkowska A, Wiszomirska H, Wojcicka A, Poplawski P, Boguslawska J, Tanski Z, et al. Disturbed expression of splicing factors in renal cancer affects alternative splicing of apoptosis regulators, oncogenes, and tumor suppressors. PLoS One. 2010; 5:e13690. [PubMed: 21082031]

45. Simeonova I, Jaber S, Draskovic I, Bardot B, Fang M, Bouarich-Bourimi R, et al. Mutant mice lacking the 553 C-terminal domain model telomere syndromes. Cell Rep. 2013; 3:2046-58. [PubMed: 23770245]

46. Marcel V, Fernandes K, Terrier O, Lane DP, Bourdon JC. Modulation of p53beta and p53gamma expression by regulating the alternative splicing of TP53 gene modifies cellular response. Cell Death Differ. 2014; 21:1377-87. [PubMed: 24926616]

47. Kern SE, Pietenpol JA, Thiagalingam S, Seymour A, Kinzler KW, Vogelstein B. Oncogenic forms of p53 inhibit p53-regulated gene expression. Science. 1992; 256:827-30. [PubMed: 1589764]

48. O'Sullivan B, Levin W. Late radiation-related fibrosis: pathogenesis, manifestations, and current management. Semin Radiat Oncol. 2003; 13:274-89. [PubMed: 12903016]

49. Oeffinger KC, Mertens AC, Sklar CA, Kawashima T, Hudson MM, Meadows AT, et al. Chronic health conditions in adult survivors of childhood cancer. N Engl J Med. 2006; 355:1572-82. [PubMed: 17035650] 
50. Ness KK, Krull KR, Jones KE, Mulrooney DA, Armstrong GT, Green DM, et al. Physiologic frailty as a sign of accelerated aging among adult survivors of childhood cancer: a report from the St Jude Lifetime cohort study. J Clin Oncol. 2013; 31:4496-503. [PubMed: 24248696]

51. Muhlemann O, Mock-Casagrande CS, Wang J, Li S, Custodio N, Carmo-Fonseca M, et al. Precursor RNAs harboring nonsense codons accumulate near the site of transcription. Mol Cell. 2001; 8:33-43. [PubMed: 11511358]

52. Iborra FJ, Jackson DA, Cook PR. Coupled transcription and translation within nuclei of mammalian cells. Science. 2001; 293:1139-42. [PubMed: 11423616]

53. Abraham RT. The ATM-related kinase, hSMG-1, bridges genome and RNA surveillance pathways. DNA Repair (Amst). 2004; 3:919-25. [PubMed: 15279777]

54. Lopez-Diaz FJ, Gascard P, Balakrishnan SK, Zhao J, Del Rincon SV, Spruck C, et al. Coordinate transcriptional and translational repression of p53 by TGF-beta1 impairs the stress response. Mol Cell. 2013; 50:552-64. [PubMed: 23706820]

55. Wang ET, Sandberg R, Luo S, Khrebtukova I, Zhang L, Mayr C, et al. Alternative isoform regulation in human tissue transcriptomes. Nature. 2008; 456:470-6. [PubMed: 18978772]

56. Levine AJ, Oren M. The first 30 years of p53: growing ever more complex. Nat Rev Cancer. 2009; 9:749-58. [PubMed: 19776744]

57. Margalit O, Amram H, Amariglio N, Simon AJ, Shaklai S, Granot G, et al. BCL6 is regulated by p53 through a response element frequently disrupted in B-cell non-Hodgkin lymphoma. Blood. 2006; 107:1599-607. [PubMed: 16249378] 


\section{STATEMENT OF SIGNIFICANCE}

We identified a new component of the DNA Damage Response Pathway (DDR) that regulates alternative splicing of messenger RNAs, including human p53 mRNA. Modulation of this regulatory pathway affects DNA damage induction of cellular senescence markers. 
A
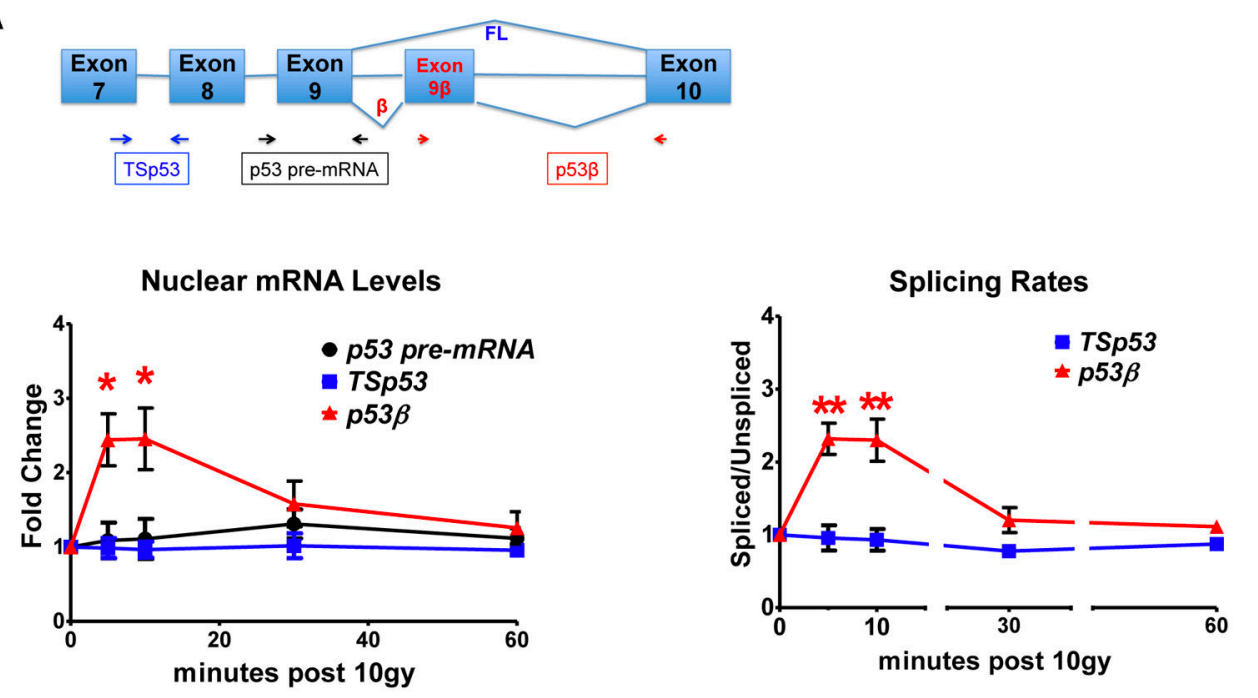

B

C
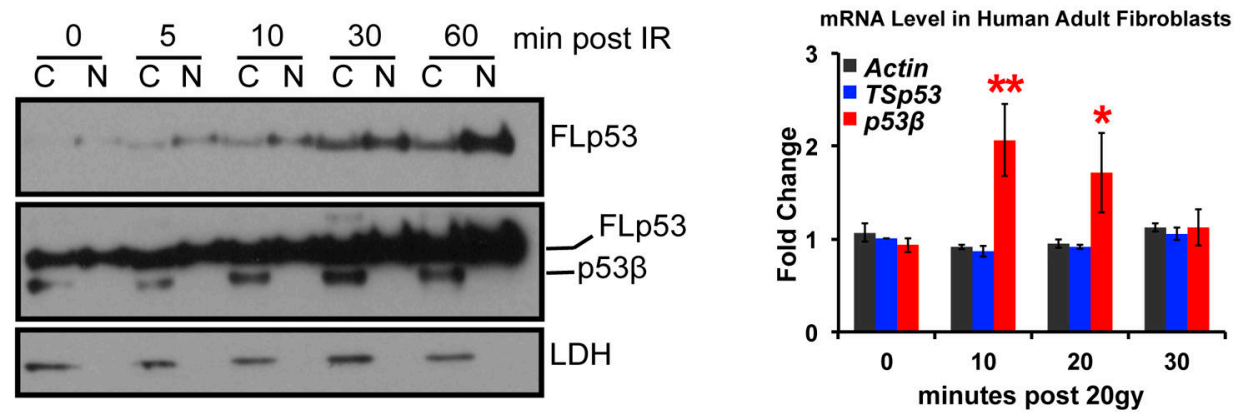

Figure 1. Ionizing Irradiation (IR) increases splicing of the p53 $\beta$ isoform

A. Time course of RT-qPCR analysis of nuclear mRNA expression (left graph) and the ratio of nuclear spliced message level/p53 pre-mRNA level (right graph) within 1hr post 10gy irradiation in MCF7 cells. Top schema highlights the region containing exon 7-10 and part of the retained Exon $9 \beta$ of p53 mRNA. The splicing processes to generate full-length (FL) p53 or the $\beta$ isoform are labeled around Exon $9 \beta$ region. Arrow pairs illustrate the approximate locations of the qPCR primers for detecting total spliced (TS) p53, p53 premRNA and $\mathrm{p} 53 \beta$ mRNA expression in RT-qPCR. Results are represented as mean \pm SEM. * $\mathrm{P} \unlhd 0.05$, ** P $₫ .01, * * * \mathrm{P} \unlhd 0.001$, t-test. FL: full length. TS: total spliced. B. Nuclear (N) and cytoplasmic (C) p53 $\beta$ protein expression in MCF7 cells asseseed by immunoblot analysis. LDH is the cytoplasmic fraction marker. C. RT-qPCR analysis of p53 $\beta$ mRNA expression in human adult fibroblasts at early passages after 20Gy irradiation. HAF at passage 11 was collected for analysis at indicated time points post 0 or 20 Gy irradiation. HAF: human adult fibroblast. Data are shown as mean \pm SEM of three independent experiments. 
A

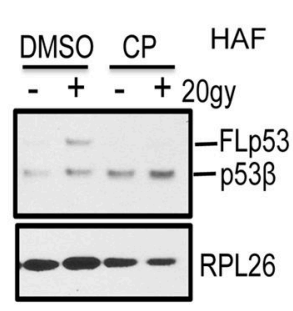

B

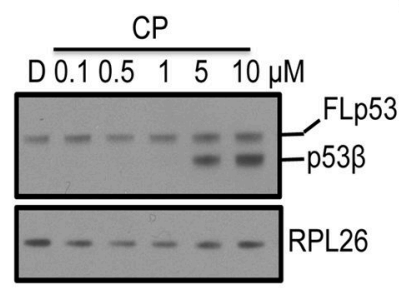

C

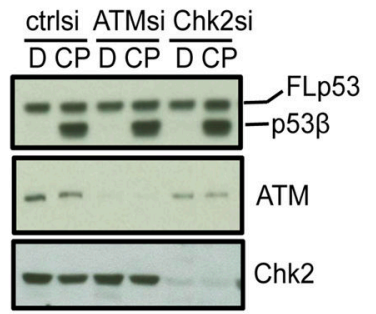

D

ctrlsi SMG1si

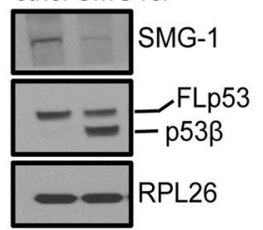

Fold Changes of Relative
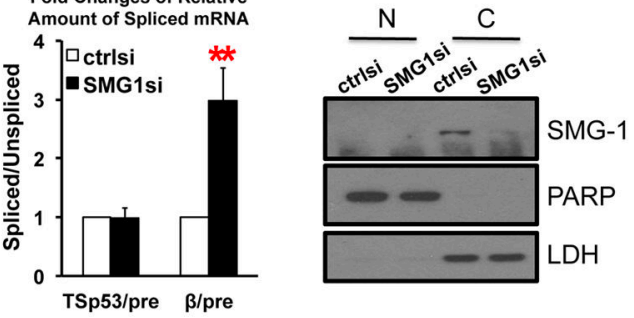

E

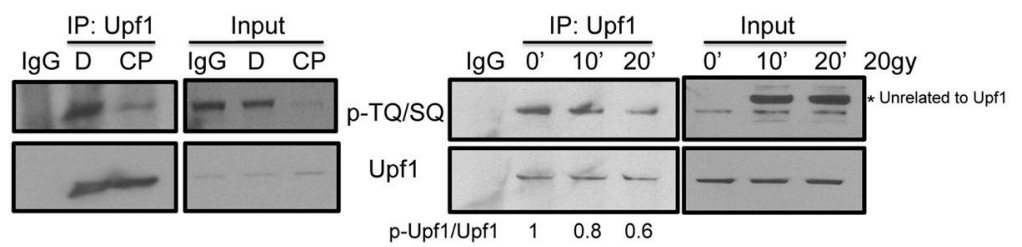

$\mathbf{F}$
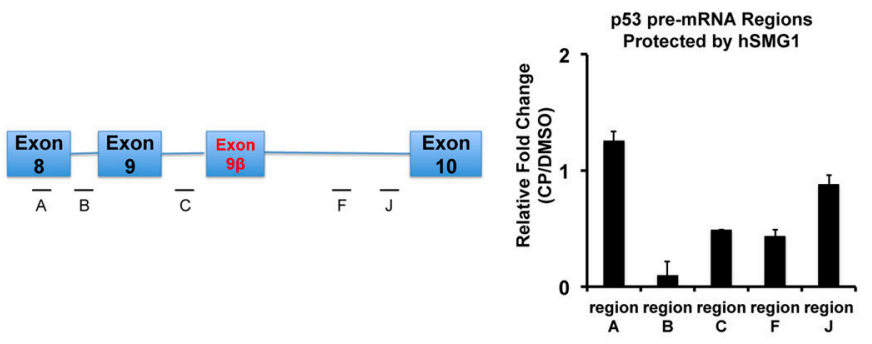

Figure 2. hSMG-1 negatively regulates p53 $\beta$ splicing

A-C. CP466722 (CP) induces p53 $\beta$ variant in an ATM-independent manner. A. Immunoblot analysis of $\mathrm{p} 53 \beta$ protein expression in primary cells. HAF at passage 23 were pretreated with $10 \mu \mathrm{M} \mathrm{CP}$ for $8 \mathrm{hr}$ and collected $15 \mathrm{~min}$ post 0 (-) or 20 (+) Gy irradiation for immunoblot. B. Immunoblot analysis of p53 $\beta$ protein expression in MCF7 cells $8 \mathrm{hr}$ post CP466722 treatment $(0-10 \mu M)$. ( $=$ DMSO). C. Immunoblot analysis of the induction of p53 $\beta$ protein by $\mathrm{CP}$ in the absence of ATM, or Chk2. MCF7 cells were transfected with indicated siRNA for 3 days followed by $8 \mathrm{hr} \mathrm{CP}$ treatment. Shown are the representative immunoblots of three independent experiments. D. p53 $\beta$ expression and splicing in the absence of hSMG-1. Immunoblot analysis of $\mathrm{p} 53 \beta$ protein expression (left panel) and the ratio of spliced message level/p53 pre-mRNA level (middle panel) assessed by RT-qPCR three days post hSMG-1 siRNA transfection in MCF7 cells. **P $₫$ 0.01, t-test. Right panel: 
Western blot analysis of nuclear and cytoplasmic hSMG-1, PARP (nuclear marker), LDH (cytoplasmic marker) protein expression 3 days post siRNA transfection. Shown are representative immunoblots and mean \pm SEM of three independent experiments. E. Representative Immunoprecipitation/Western blot (IP/WB) analysis of phosphorylated Upf1 after CP or IR treatment. Upf1 immunoprecipitated from MCF7 cells treated with $10 \mu \mathrm{M} \mathrm{CP}$ for $8 \mathrm{hr}$ (left panel) or at indicated time points posts 20gy irradiation (right panel) was immunoblotted with pan-phospho-S/TQ antibody to assess the level of phosphorylated Upf1 and subsequently reblotted with anti-Upf1 antibody for total Upf1 protein expression. F. RNase mediated footprint of hSMG1 binding at different regions of $\mathrm{p} 53$ pre-mRNA post $\mathrm{CP}$ treatment. After $8 \mathrm{hr}$ exposure to $\mathrm{CP}$ followed by formaldehyde crosslinking, hSMG1 immunoprecipitants from MCF7 cells were subjected to RNase treatment. hSMG1 protected regions of p53 pre-mRNA were detected using RT-qPCR. Left: location of regions investigated in the experiment. Right: relative fold change was the fold change of detected region in CP vs DMSO treated samples. 
A
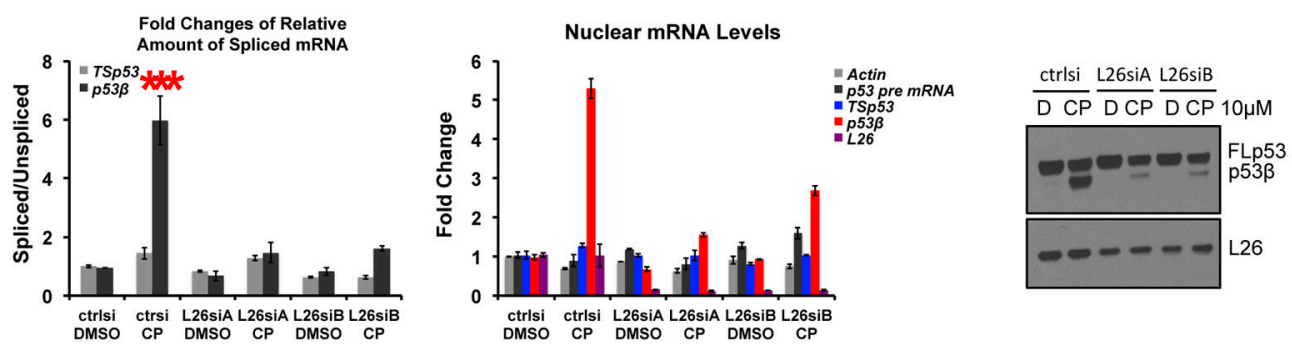

B
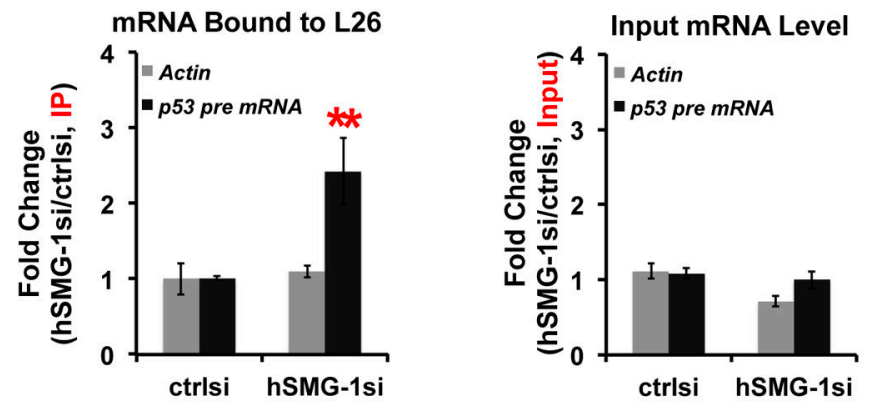

Figure 3. RPL26 is a positive regulator of $p 53 \beta$ splicing

A. $p 53 \beta$ splicing in the absence of RPL26. Left: Relative amount of p53 $\beta$ (p53 $\beta$ mRNA/p53 pre-mRNA) in MCF7 cells transfected with two different RPL26 siRNAs (L26siA, L26siB) for 3 days before $10 \mu \mathrm{M} \mathrm{CP}$ or DMSO treatment for 8hr. Right: RT-qPCR analysis of nuclear mRNA levels in MCF7 cells with the same treatment as described above. ***P $₫ 0.001$, t-test. B. Enrichment of p53 pre-mRNA on nuclear RPL26 in the absence of hSMG-1. The bound mRNAs in nuclear RPL26 immunoprecipitated from MCF7 cells transfected with hSMG-1 siRNA for 3 days were subjected to RT-qPCR analysis. Left: mRNA levels detected in RPL26-immunoprecipitate from nuclear fraction. Right: mRNA expression in input nuclear fraction. Shown are mean \pm SEM of three independent experiments. **P $₫$.01, t-test. 
A

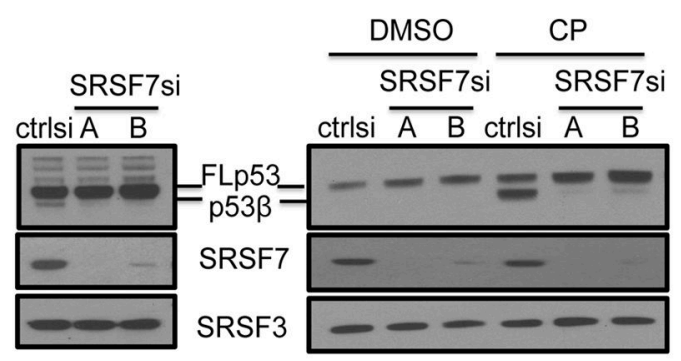

B

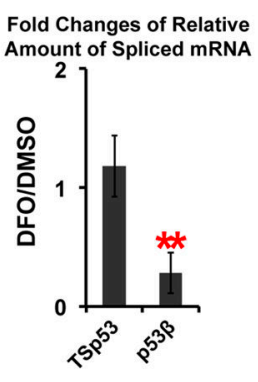

D
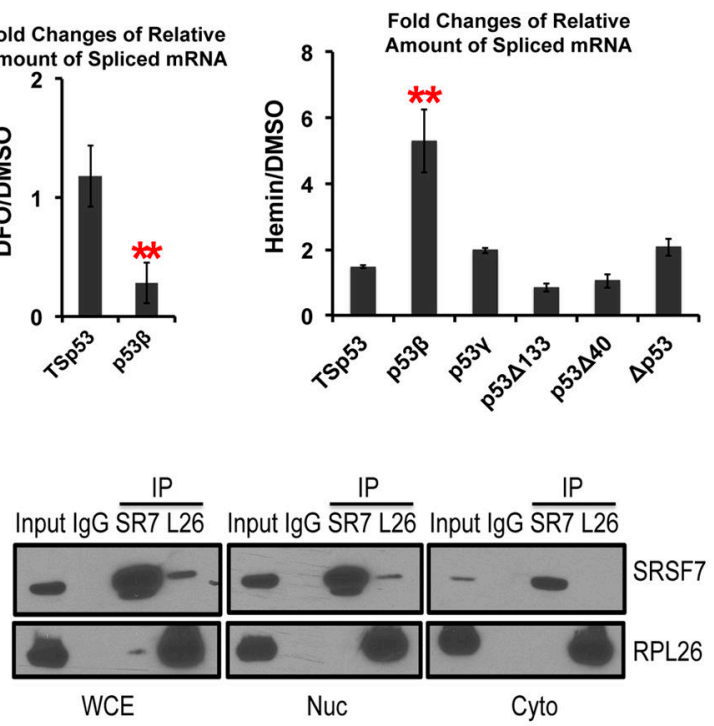

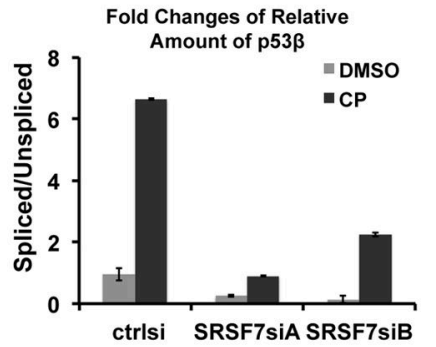

C

mRNA Bound to SRSF7

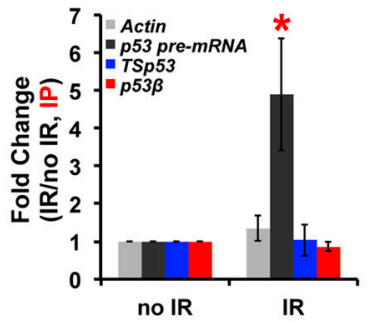

Input mRNA Level

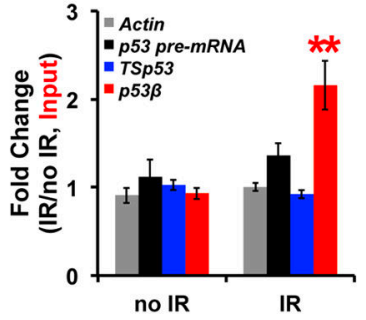

E
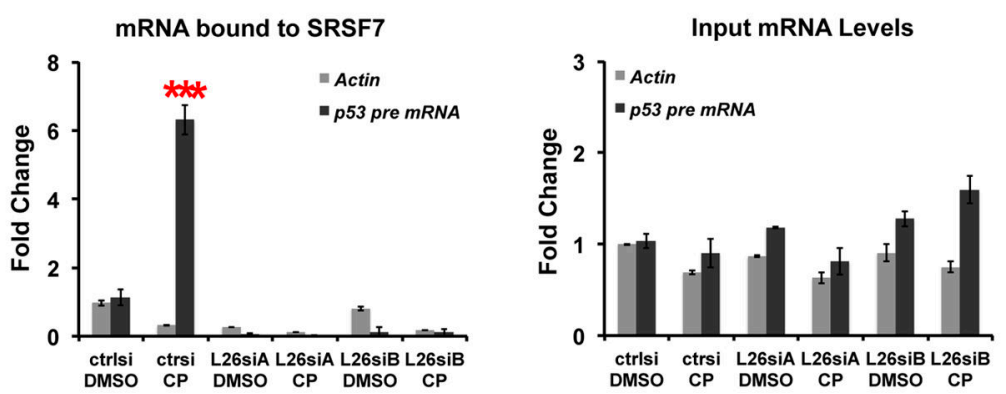

Figure 4. SRSF7 positively regulates the alternative splicing of p53 $\beta$ in an iron-dependent manner

A. Analysis of $\mathrm{p} 53 \beta$ protein expression and splicing in the absence of SRSF7. Left panel: Immunoblot analysis of $\mathrm{p} 53 \beta$ protein expression in MCF7 transfected with two different SRSF7 siRNAs for 3 days. Middle panel: Immunoblot analysis of $\mathrm{p} 53 \beta$ protein expression in MCF7 cells transfected with SRSF7 siRNAs for 3 days plus 10 $\mu \mathrm{M}$ CP or DMSO treatment for the last $8 \mathrm{hr}$. Right panel: RT-qPCR analysis of p53 $\beta$ splicing in MCF7 cells with the same treatment as described above. B. RT-qPCR analysis of $p 53 \beta$ splicing in the presence of iron modulators. Left panel: RT-qPCR analysis of p53 $\beta$ splicing in MCF7 cells treated with $100 \mu \mathrm{M}$ desferoxamine (DFO) for $24 \mathrm{hr}$ or treated with $100 \mu \mathrm{M}$ Hemin for $8 \mathrm{hr}$ (right panel). The ratios of relative $\mathrm{p} 53 \beta$ mRNA level (p53 $\beta$ mRNA/p53 pre-mRNA) before 
and after treatment were presented. Shown are representative immunoblots and mean \pm SEM of three independent experiments. C. Analysis of nuclear SRSF7-bound mRNA expression. Nuclear SRSF7 was immunoprecipitated from MCF7 cells 15 min post 20gy irradiation. RTqPCR analysis of immunoprecipitated (top graph) and input (bottom graph) nuclear mRNA presented as mean \pm SEM of three independent experiments. D. Reciprocal coimmunoprecipitation of SRSF7 and RPL26 was performed in whole cell extract (WCE), nuclear fraction (Nuc) and cytoplasmic fraction (Cyto) followed by immunoblot analysis for bound RPL26 or SRSF7, respectively. IgG was used as a negative control for immunoprecipitation. 10\% lysate before IP was loaded as input. Shown are representative immunoblots of three independent experiments. E. Analysis of SRSF7-bound mRNA expression in the absence of RPL26. Nuclear SRSF7 was immunoprecipitated from MCF7

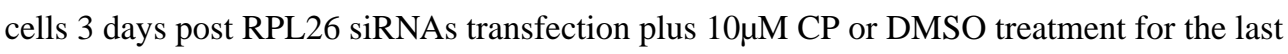
8hr. RT-qPCR analysis of IPed (left graph) and input (right graph) nuclear mRNA levels are presented as mean \pm SEM of three independent experiments. ***P $₫ 0.001$, t-test. 
A
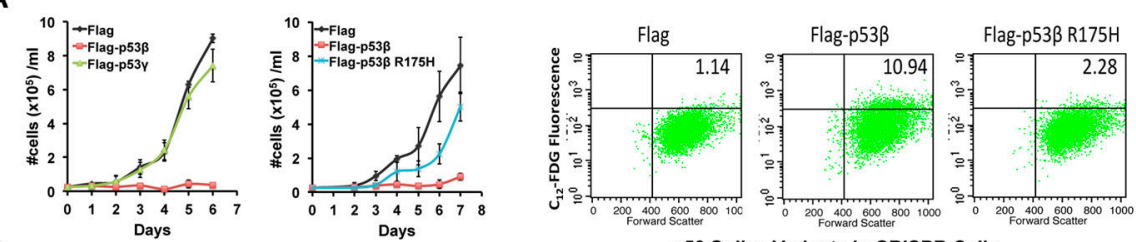

B
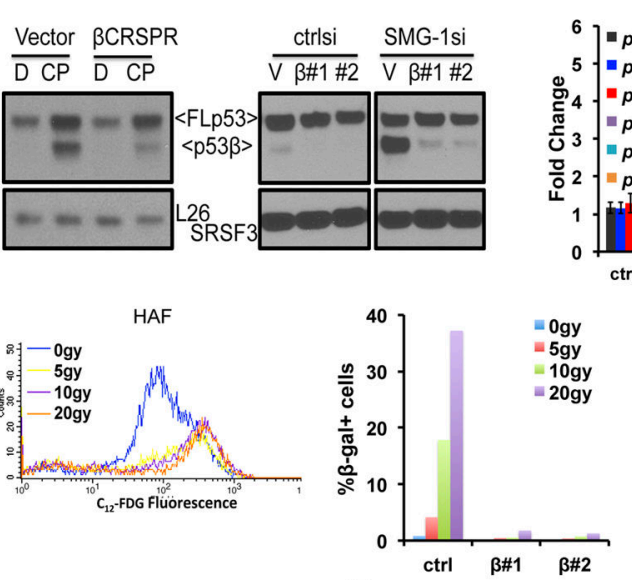

p53 Splice Variants in CRISPR Cells

C
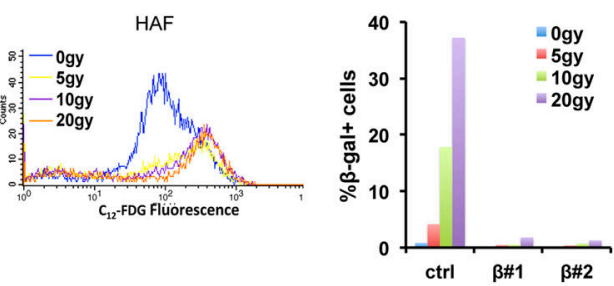

53 pre-mRNA

053 pl

5 - $=p 53$

$4-p 53 \beta$

ป $3-p 53 \Delta 133$

응 2 - $=p 53 y$

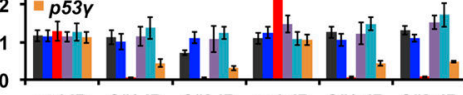

ctrl-IR $\quad \beta \# 1-I R \quad \beta \# 2-I R \quad$ ctrl+IR $\quad \beta \# 1+I R \quad \beta \# 2+I R$

E

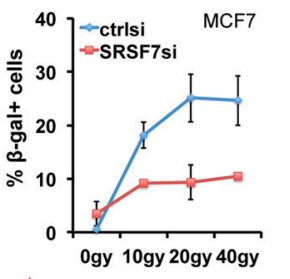

$\mathbf{F}$
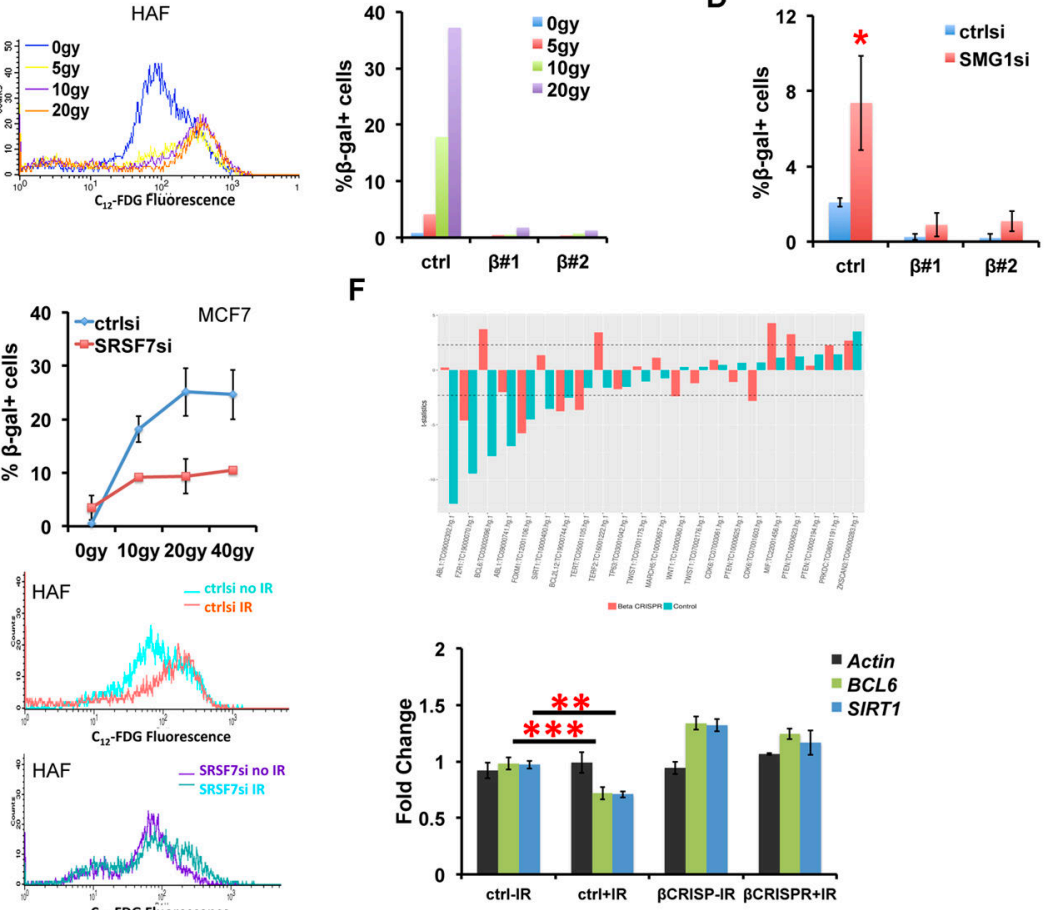

Figure 5. p53 $\beta$ regulates cellular senescence

A. Phenotypes of p53 $\beta$-overexpressing stable cell lines. Left panel: Growth curve of MCF7 stable lines constitutively expressing empty vector (Flag), Flag-p53 $\beta$, Flag-p53 $\gamma$ or Flagp53 3 R175H. Data are quantifications from three independent experiments. Right panel: Dot plot for flow SA- $\beta$-galactosidase activity assay. The percentage of SA- $\beta$-gal positive cells (upper right quadrant) is quantitated. Shown are representative data of three independent experiments. B. Generation and characterization of p53 $\beta$ CRISPR knockout lines. Left panel: Immunoblot analysis of p53 $\beta$ protein expression in pooled CRISPR knockout lines ( $\beta$ CRISPR) treated with $10 \mu \mathrm{M} \mathrm{CP}$ for $8 \mathrm{hr}$. Middle panel: Immunoblot analysis of $\mathrm{p} 53 \beta$ protein expression in two p53 $\beta$ CRISPR knockout clones $(\beta \# 1, \beta \# 2)$ transfected with control siRNA (ctrlsi) or hSMG-1 siRNA (SMG1si) for 3 days. (Note: the faint $\sim 48 \mathrm{kd}$ protein band remaining in the $\beta$ CRISPR knockout cells is $\mathrm{p} 53 \gamma$ protein, which is also recognized by the p53 antibody.) Right graph: RT-qPCR analysis of p53 $\beta$ mRNA expression in control and 
p53 $\beta$ CRISPR knockout clones 15 min post 0 (-) or $20(+)$ Gy irradiation. Shown are mean \pm SEM of three independent experiments. (Note: no p53 $\beta$ mRNA is detectable in the knockout cells.) C. Flow SA- $\beta$-galactosidase activity assay in primary fibroblasts and p53 $\beta$ CRISPR knockout clones after IR. Left graph: $\mathrm{C}_{12}$-FDG fluorescein fluorescence histogram for the relative levels of $\beta$-galactosidase activity in HAF (passage 11) 6 days after various doses of irradiation. Right graph: Quantification of SA- $\beta$-galactosidase positive cells in $\mathrm{p} 53 \beta$ CRISPR knockout clones $(\beta \# 1, \beta \# 2) 5$ days post 0 to $20 \mathrm{gy}$ irradiation. D. Quantification of SA- $\beta$-galactosidase positive cells in p53 $\beta$ CRISPR knockout clones $(\beta \# 1, \beta \# 2) 5$ days post hSMG-1 siRNA transfection. Data are mean \pm SEM of three independent experiments. $E$. Quantification of SA- $\beta$-galactosidase positive cells in the absence of SRSF7. Flow SA- $\beta$ galactosidase activity assay was performed in MCF7 (Top graph) and HAF at passage 21 (Bottom panels) 3 days post SRSF7 siRNA and 6 days after 0 to 40gy and 20gy irradiation, respectively. SA- $\beta$-gal positive MCF7 cells (Top graph) were quantified as described in A. Data are mean \pm SEM of three independent experiments. Bottom panels are representative histograms of two independent experiments. F. Differential gene expression in "Negative regulation of cell aging (GO:0090344)" pathway. $t$ statistics were calculated to determine if the gene expression level is significantly changed $4 \mathrm{hr}$ post $20 \mathrm{gy}$ irradiation. The t statistics plot for all the genes in "Negative regulation of cell aging" pathway in control (blue) and p53 $\beta$ CRSIPR knockout (red) group is shown in top graph. Bottom graph: RT-qPCR analysis of SIRT1 and BCL6 gene in control \pm IR and $\beta$ CRISPR cells \pm IR. Data are mean \pm SEM of three independent experiments. *P $₫ .05, * * \mathrm{P} \unlhd) .01, * * * \mathrm{P} \unlhd) .001$, t-test. 
A
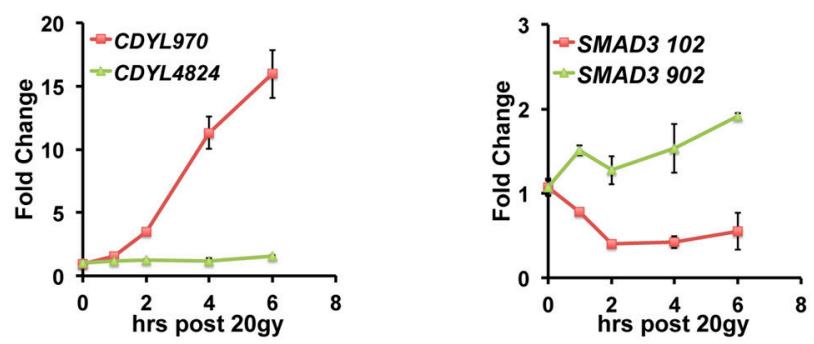

B

C

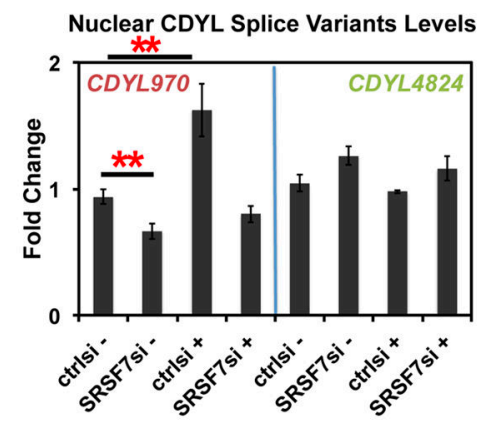

D
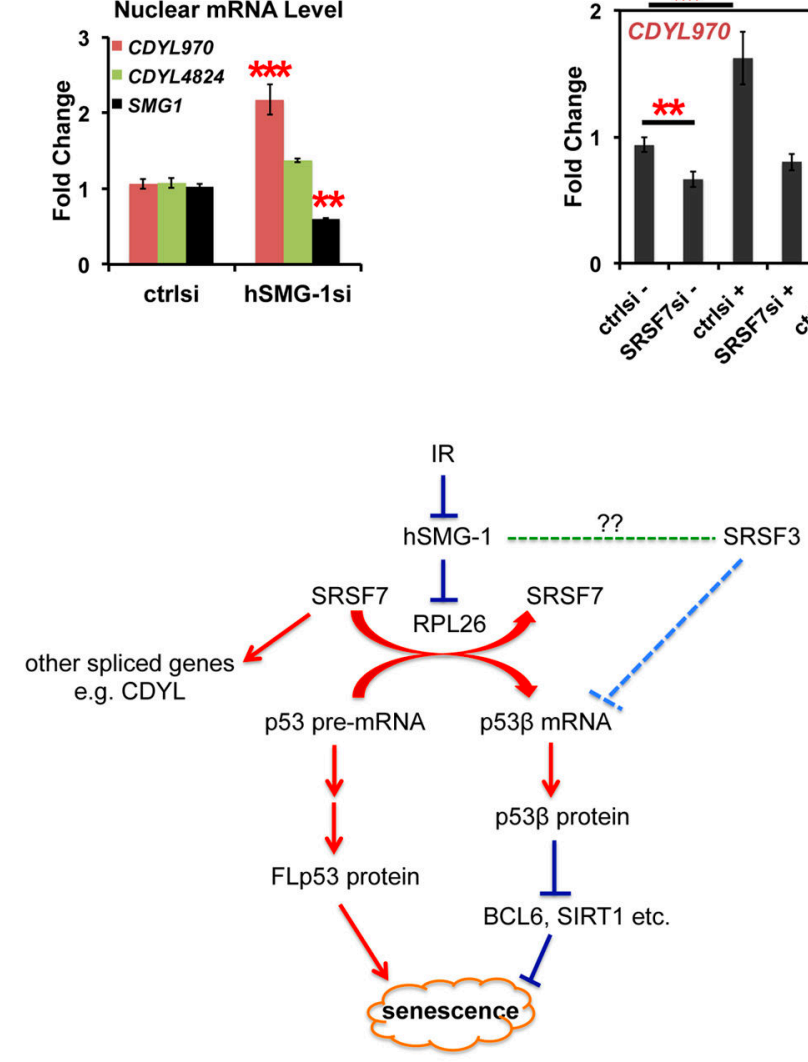

Figure 6. IR induced alternative splicing (AS)

A. Analysis of IR-induced alternative splicing of CDYL, SMAD3 in MCF7 cells. B. RTqPCR analysis of nuclear CDYL splice variants in MCF7 cells transfected with hSMG-1 siRNA for 3 days. C. RT-qPCR analysis of nuclear CDYL splice variants in MCF7 cells transfected with SRSF7 siRNA for 3 days and $2 \mathrm{hr}$ post 0 (-) or 20 (+) Gy irradiation. Data are mean \pm SEM of three independent experiments. D. Model of the new DDR signaling pathway. *P $₫ .05, * * \mathrm{P} \unlhd(01, * * * \mathrm{P} \unlhd \mathbf{0} .001$, t-test. 